Supporting Information

\title{
Stable Yellow Light-Emitting Devices Based on Ternary Copper Halides with Broadband Emissive Self-Trapped Excitons
}

Zhuangzhuang Ma, ${ }^{1}$ Zhifeng Shi, ${ }^{*},{ }^{1}$ ChaoChao Qin, ${ }^{2}$ Minghuan Cui, ${ }^{2}$ Dongwen Yang, ${ }^{1}$ Xinjiang

Wang, ${ }^{3}$ Lintao Wang, ${ }^{1}$ Xinzhen $J i,{ }^{1}$ Xu Chen, ${ }^{1}$ Junlu Sun, ${ }^{1,4}$ Di Wu, ${ }^{1}$ Yu Zhang, ${ }^{5}$ Xin Jian Li, ${ }^{1}$ Lijun

Zhang, ${ }^{* 3}$ and Chongxin Shan ${ }^{*, 1}$

${ }^{1}$ Key Laboratory of Materials Physics of Ministry of Education, School of Physics and

Microelectronics, Zhengzhou University, Daxue Road 75, Zhengzhou 450052, China

${ }^{2}$ Henan Key Laboratory of Infrared Materials \& Spectrum Measures and Applications, Henan Normal University, Jianshe Road 46, Xinxiang 453007, China

${ }^{3}$ State Key Laboratory on Integrated Optoelectronics, Key Laboratory of Automobile Materials of MOE, and College of Materials Science and Engineering, Jilin University, Qianjin Street 2699, Changchun 130012, China

${ }^{4}$ CAS Center for Excellence in Nanoscience, Beijing Key Laboratory of Micro-Nano Energy and Sensor, Beijing Institute of Nanoenergy and Nanosystems, Chinese Academy of Sciences, Beijing 100083, China

${ }^{5}$ State Key Laboratory on Integrated Optoelectronics, College of Electronic Science and Engineering, Jilin University, Qianjin Street 2699, Changchun 130012, China

\footnotetext{
${ }^{*}$ Correspondence and requests for materials should be addressed to Z.S. (email: shizf@zzu.edu.cn), L.Z. (email: lijun_zhang@jlu.edu.cn) or to C.S. (email: cxshan@zzu.edu.cn).
} 


\section{Crystal structure of $\mathrm{CsCu}_{2} \underline{\mathbf{I}}_{3}$}

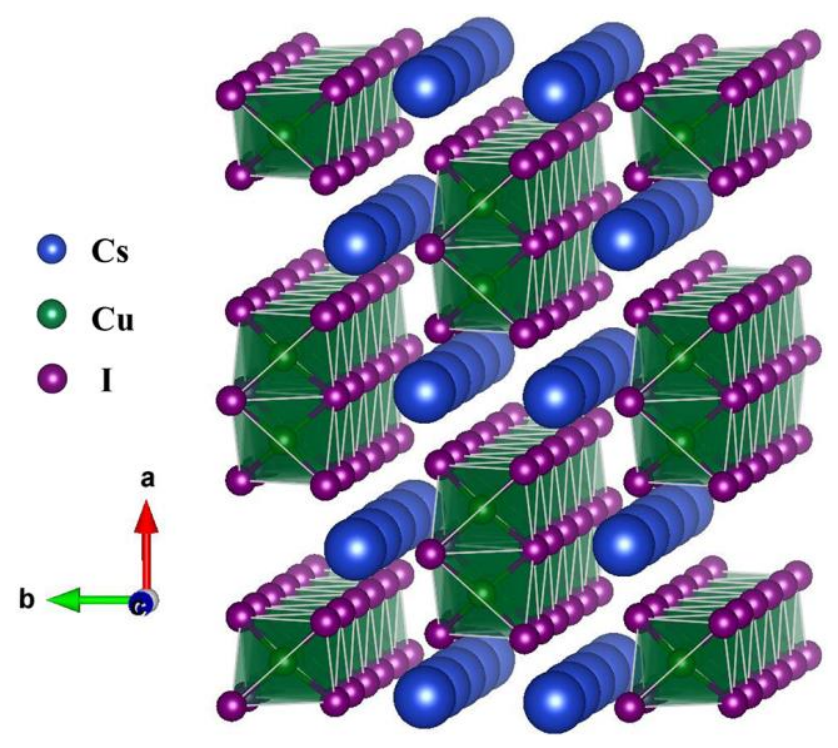

Figure S1. One-dimensional (1D) crystal structure of $\mathrm{CsCu}_{2} \mathrm{I}_{3}$ (blue: $\mathrm{Cs}$ atom; purple: I atom; green: $\mathrm{Cu}$ atom; dark green octahedron: $\mathrm{Cu}-\mathrm{I}$ tetrahedron). 


\section{$\underline{\text { Spin-coating speed-time profile }}$}

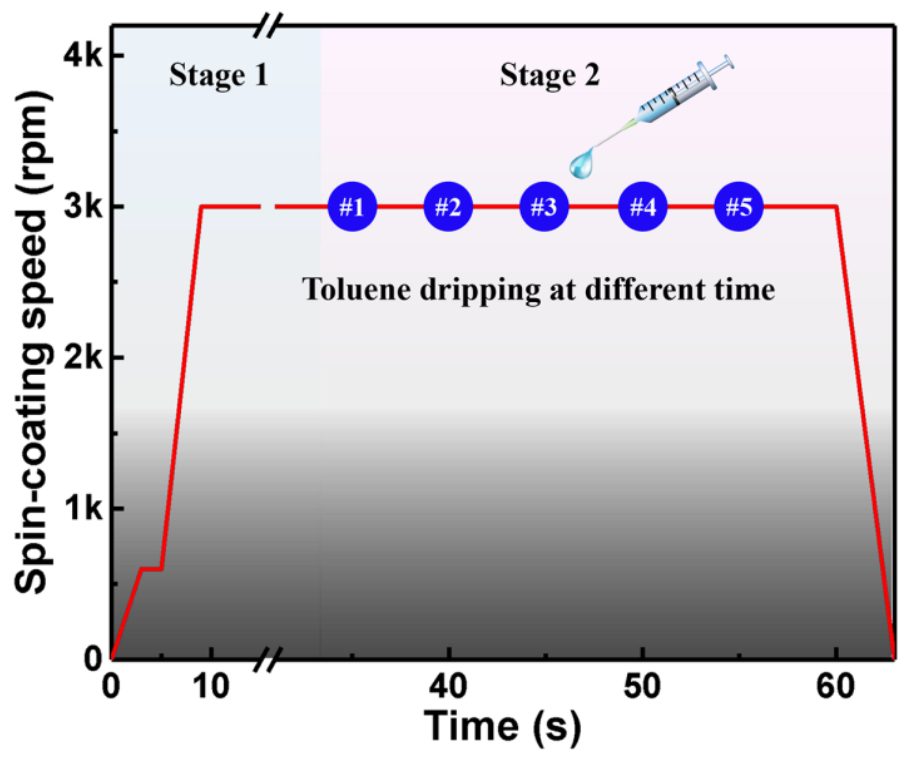

Figure S2. Spin-coating speed-time profile for preparing $\mathrm{CsCu}_{2} \mathrm{I}_{3}$ thin films. 


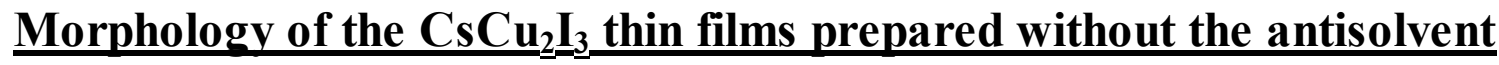

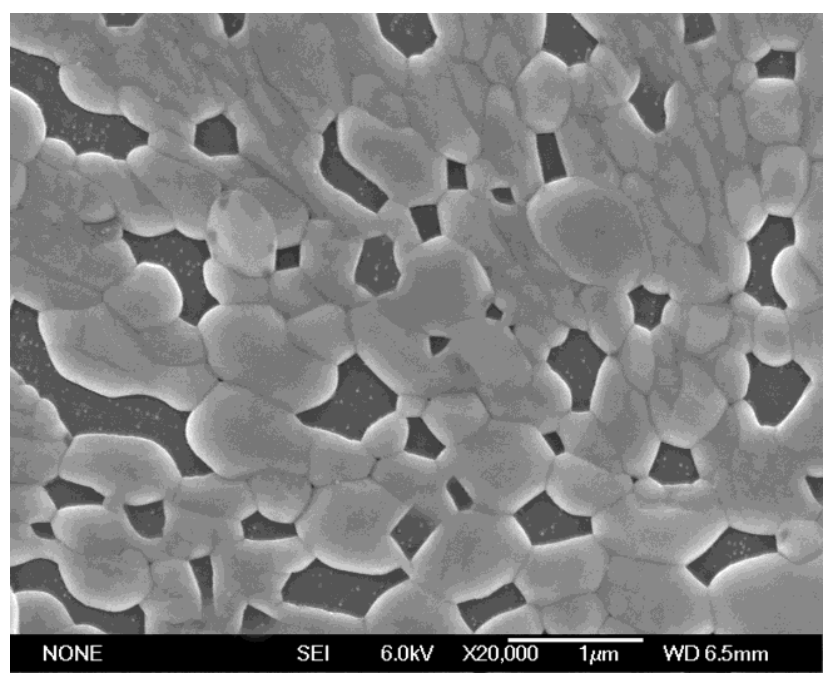

Figure S3. SEM image of the $\mathrm{CsCu}_{2} \mathrm{I}_{3}$ thin films prepared without toluene as the antisolvent. 


\section{Comparison on the surface roughness of five $\mathrm{CsCu}_{2} \underline{I}_{3}$ thin films samples}

(a)

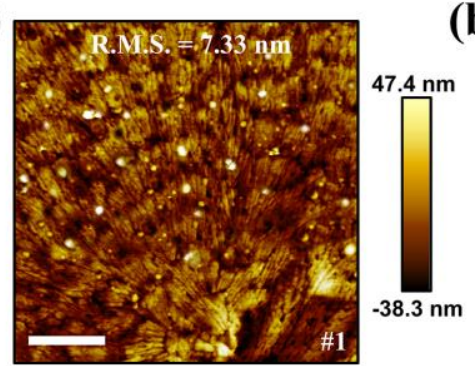

(d)

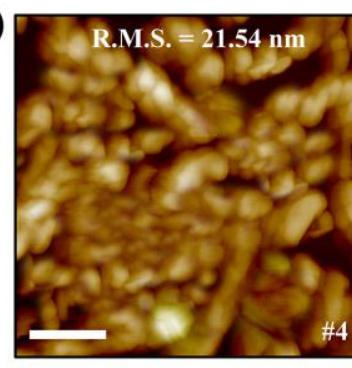

(b)

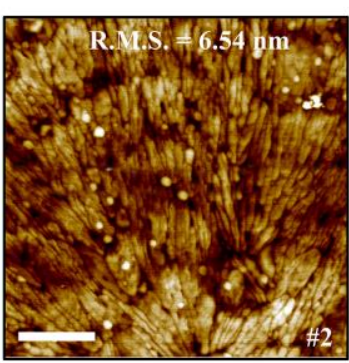

(e)

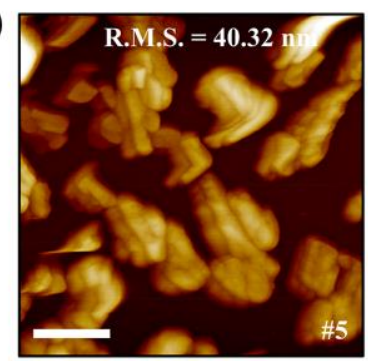

(c)



(f)

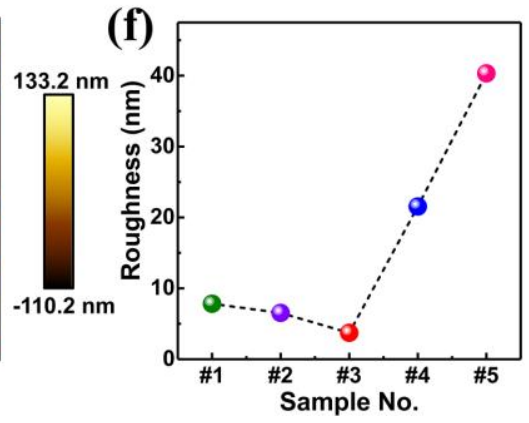

Figure S4. AFM images of the $\mathrm{CsCu}_{2} \mathrm{I}_{3}$ thin films prepared with different dripping time of the toluene antisolvent: (a) \#1, $35 \mathrm{~s}$; (b) \#2, $40 \mathrm{~s}$; (c) \#3, $45 \mathrm{~s}$; (d) \#4, $50 \mathrm{~s}$; (e) \#5, 55 s. All scale bars are $1 \mu \mathrm{m}$. (f) Summary of root-mean-square roughness of the $\mathrm{CsCu}_{2} \mathrm{I}_{3}$ thin films prepared with different conditions. 


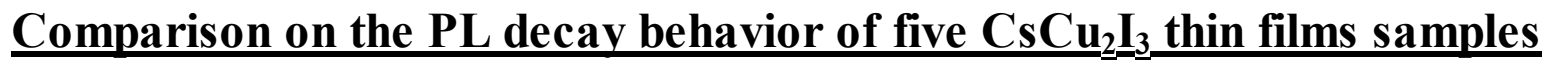

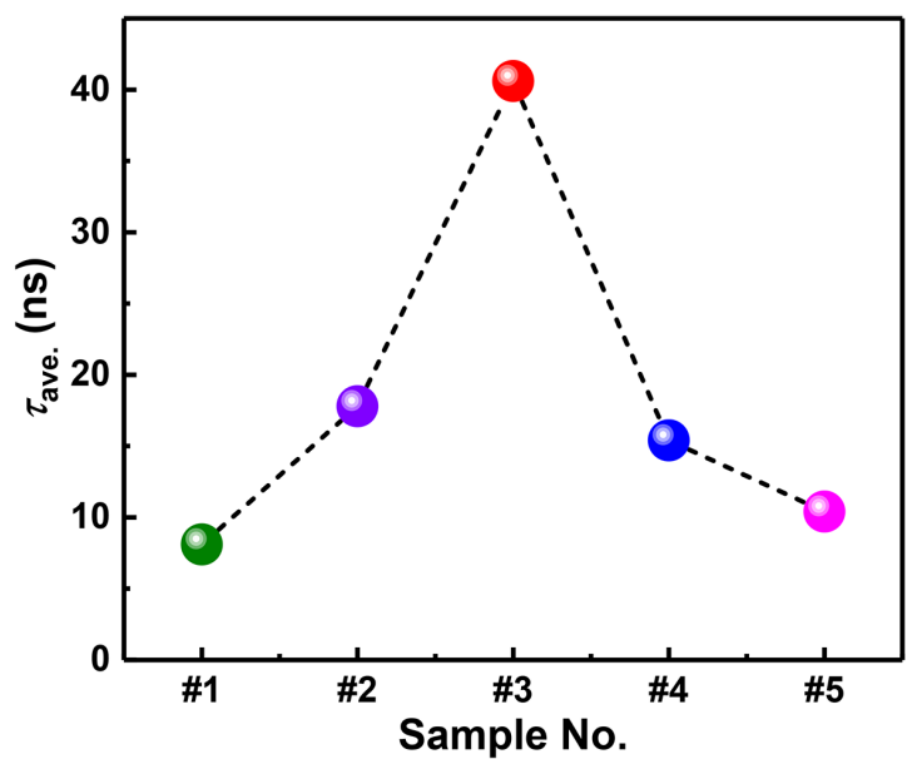

Figure S5. Average PL life time of the $\mathrm{CsCu}_{2} \mathrm{I}_{3}$ thin films obtained with different dripping time of toluene. 


\section{Dependence of the photon energy on the measured temperature}

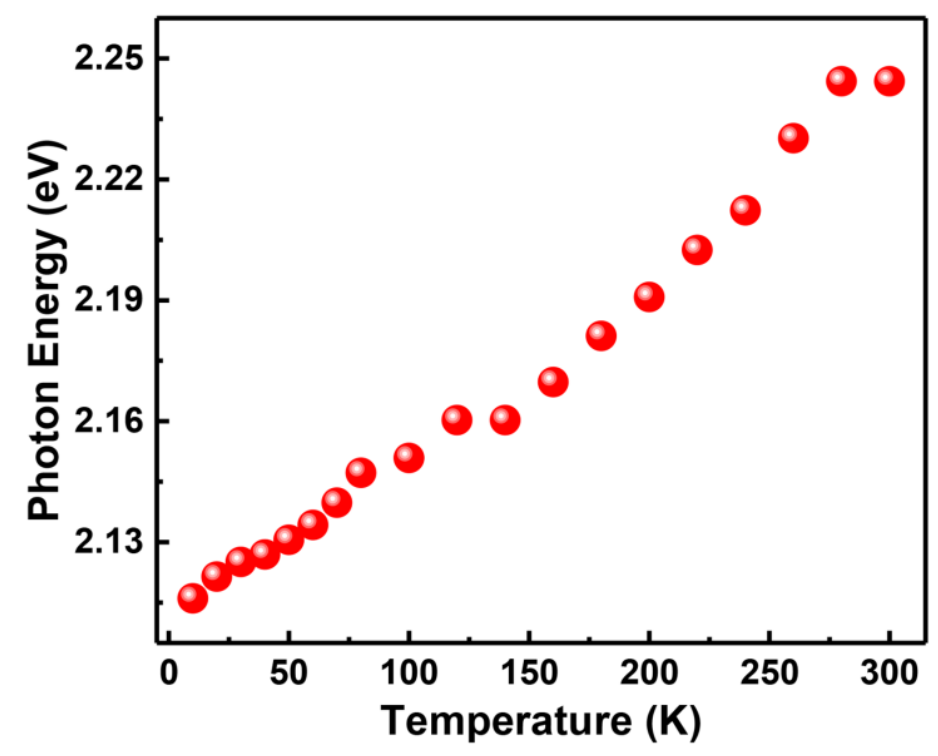

Figure S6. Shift of the photon energy of the $\mathrm{CsCu}_{2} \mathrm{I}_{3}$ thin films as a function of measured temperature (10 to $300 \mathrm{~K})$. 


\section{Estimation of the specific formation time of STES}



Figure S7. PIA onsets of the $\mathrm{CsCu}_{2} \mathrm{I}_{3}$ probed at different wavelengths. 


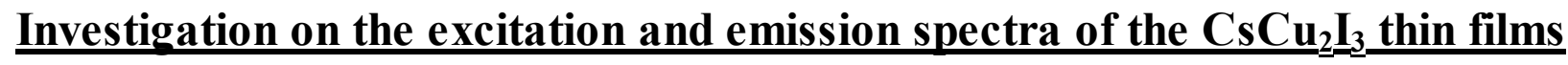
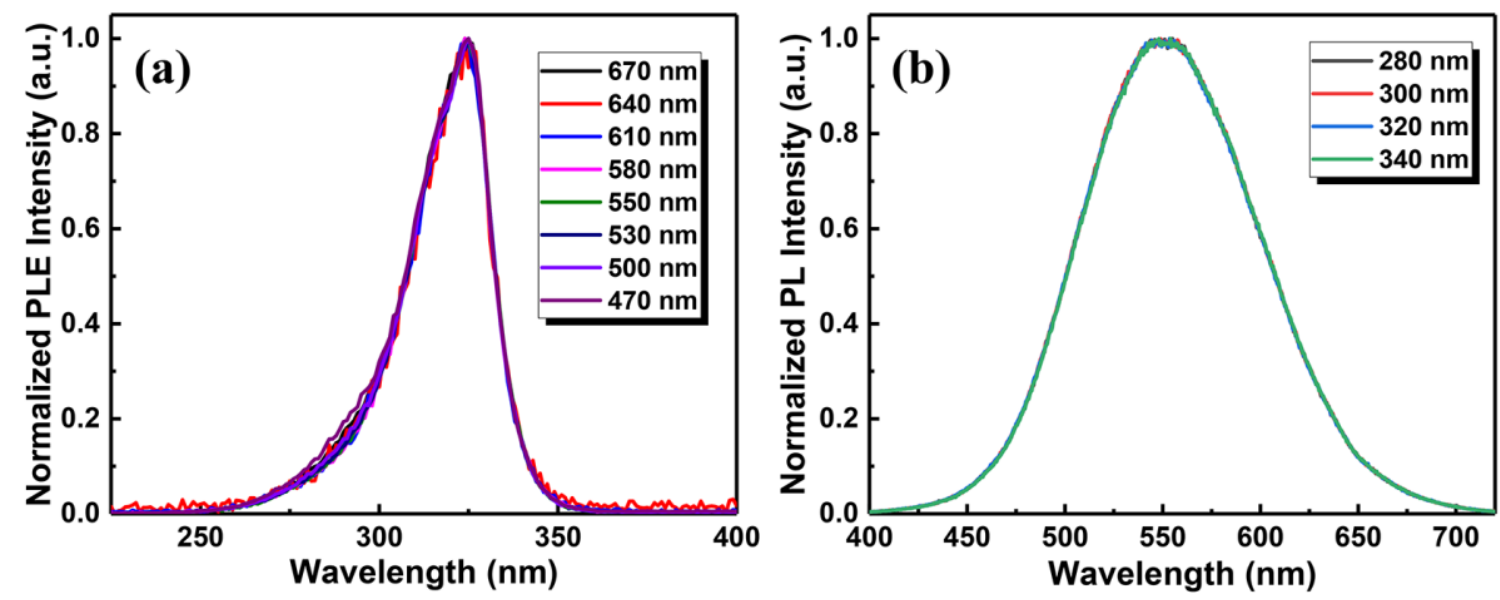

Figure S8. (a) Normalized excitation spectra of the $\mathrm{CsCu}_{2} \mathbf{I}_{3}$ thin films for the emission from 470 to $670 \mathrm{~nm}$. (b) Normalized PL spectra of the $\mathrm{CsCu}_{2} \mathrm{I}_{3}$ thin films measured at different excitation wavelengths. 


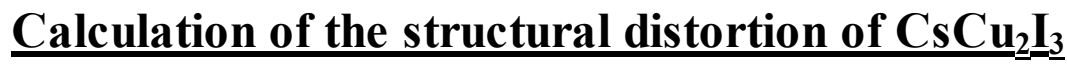
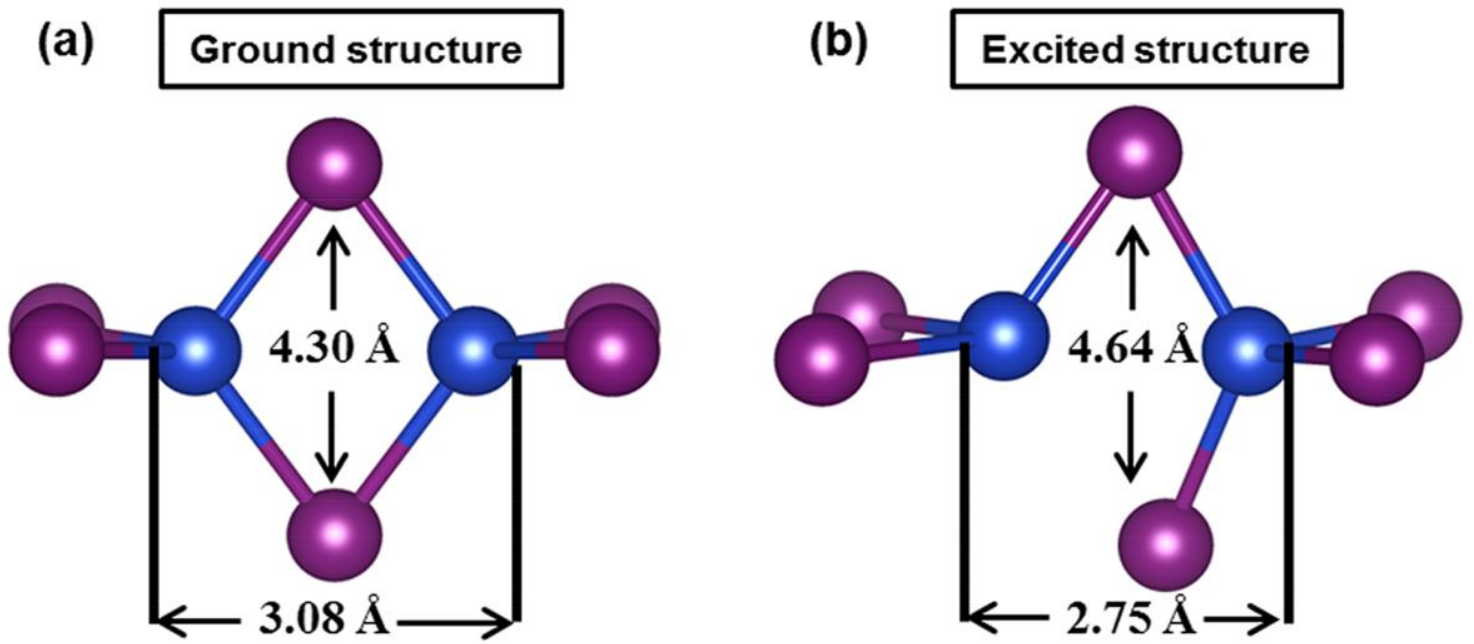

Figure S9. The geometric (a) ground state, and (b) excited state structures of CsCu $\mathbf{C}_{3}$. 


\section{Photograph of the fabricated device}



Figure S10. Photograph of the fabricated device consisting of four emitting units. The active area of each unit is $2 \times 2 \mathrm{~mm}^{2}$. 


\section{Comparison of the device performances of five devices}
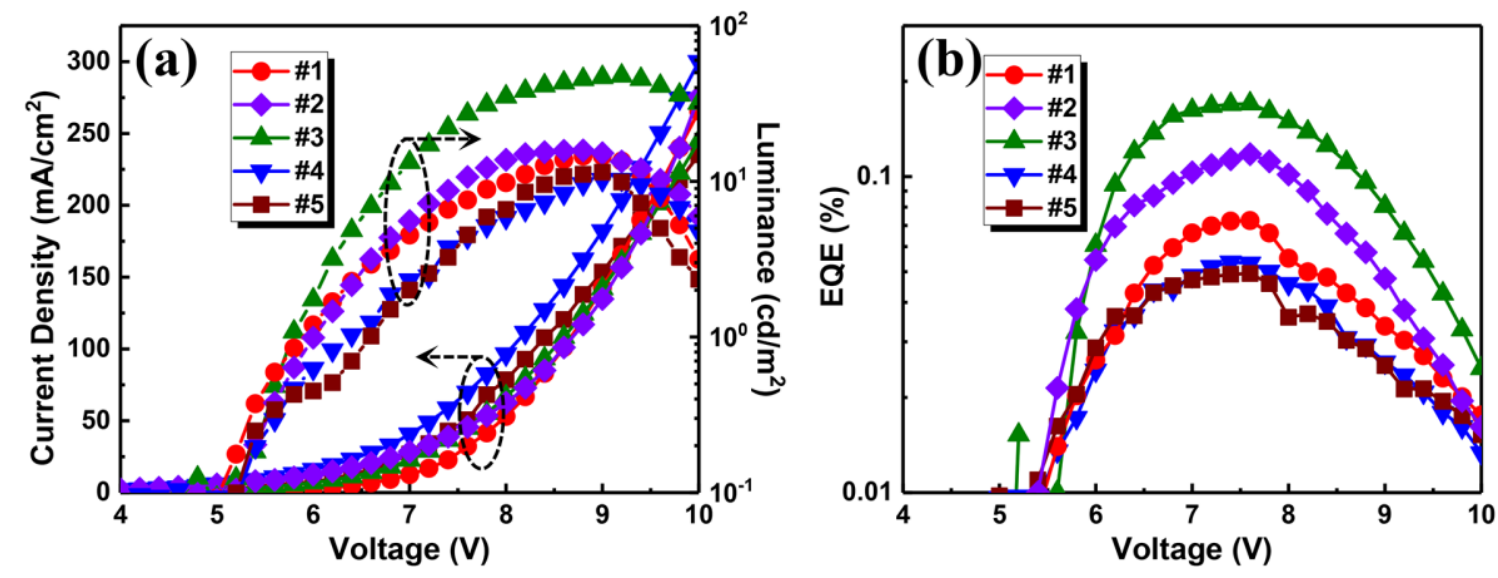

Figure S11. (a) Current density-voltage-luminance, and (b) EQE curves of the LEDs prepared with different dripping conditions of the $\mathrm{CsCu}_{2} \mathrm{I}_{3}$ thin films. 


\section{Assessment of the reproducibility of the studied LEDs}
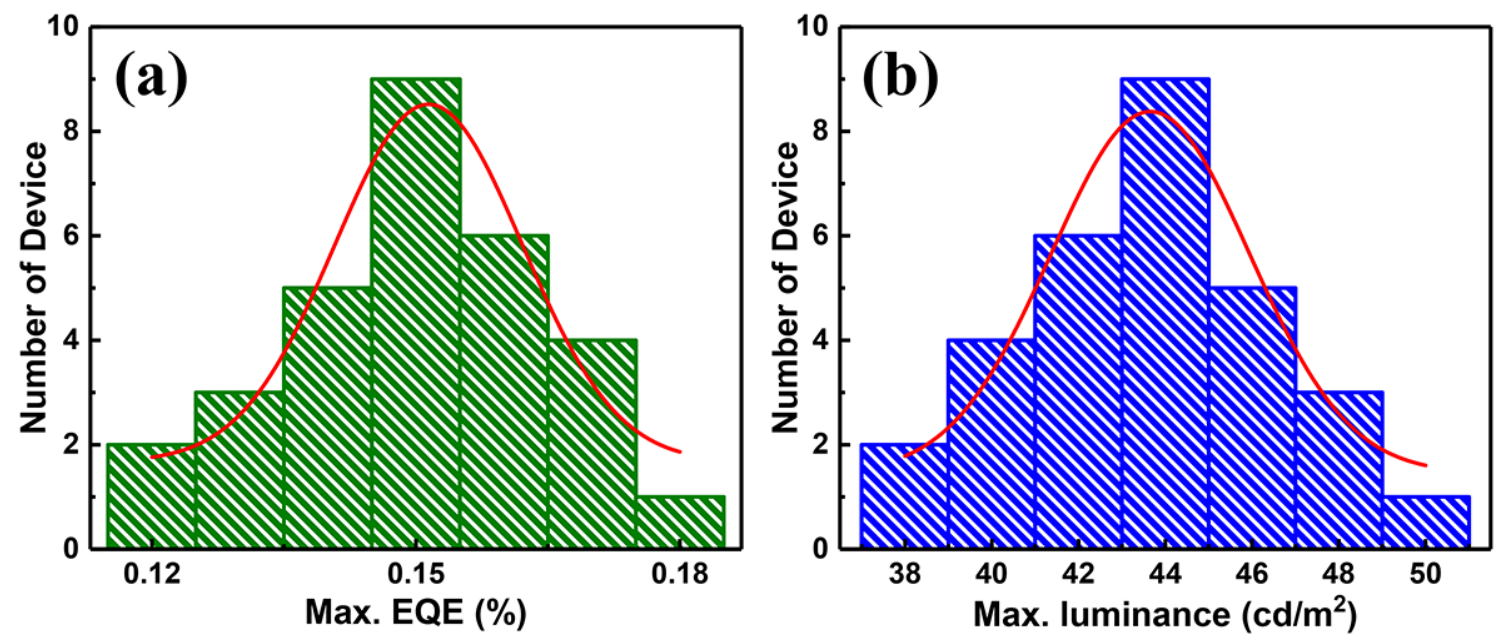

Figure S12. Statistical diagram of the (a) maximum EQE, and (b) maximum luminance measured from 30 devices with the same device structure. 


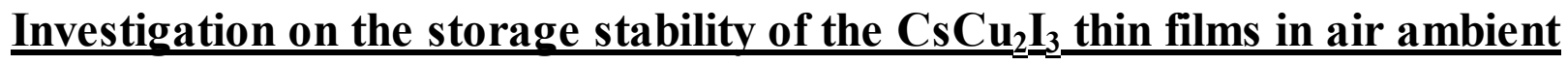

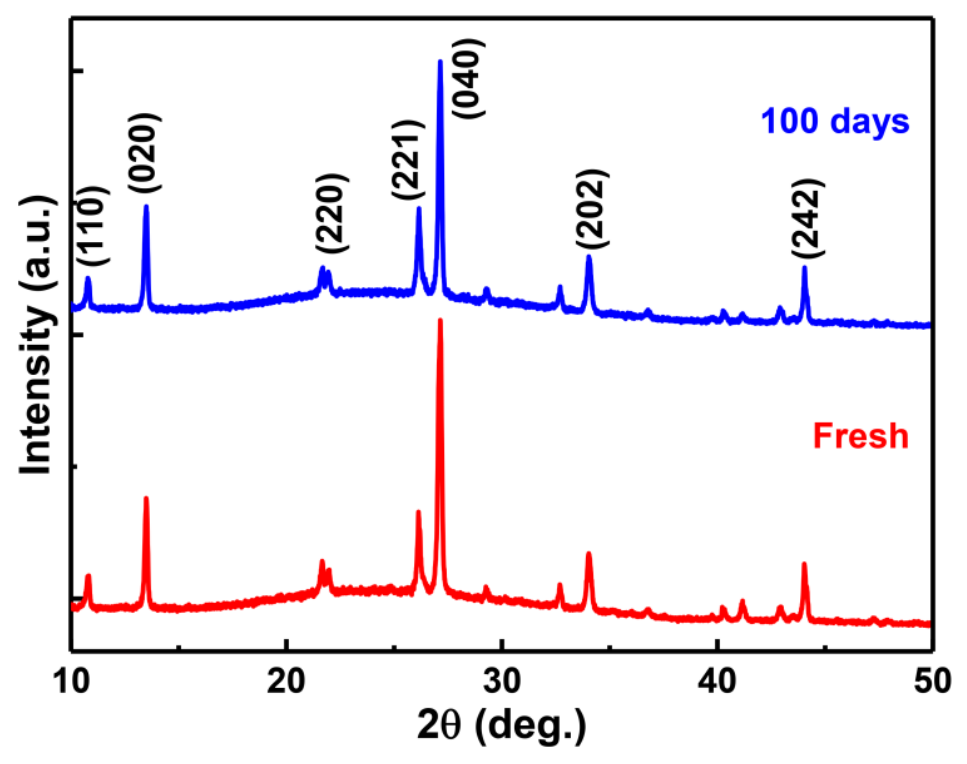

Figure S13. Comparison of the XRD patterns of the $\mathrm{CsCu}_{2} \mathrm{I}_{3}$ thin films before and after storage for 100 days in air ambient. 
Table S1 The calculated bandgap, effective masses of electron and hole,

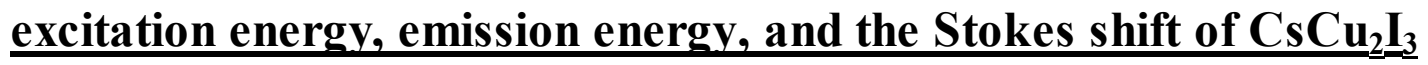

\begin{tabular}{c|c|c|c|c|c|c|c}
\hline \multirow{2}{*}{$\begin{array}{c}\text { Bandgap } \\
(\mathrm{eV})\end{array}$} & \multicolumn{2}{|c|}{$\begin{array}{c}\text { Effective mass } \\
\left(m_{0}\right)\end{array}$} & $\begin{array}{c}\text { Excitation } \\
\text { energy (eV) }\end{array}$ & energy (eV) & $\begin{array}{c}\text { Stokes shift } \\
(\mathrm{nm})\end{array}$ \\
\hline \multirow{2}{*}{$\mathrm{CsCu}_{2} \mathrm{I}_{3}$} & \multirow{2}{*}{4.02} & & $m_{\mathrm{e}}$ & $m_{\mathrm{h}}$ & 4.02 & 2.37 & 213.03 \\
\cline { 3 - 5 } & & $\Gamma \rightarrow S$ & 0.22 & 0.55 & $\left(3.82^{\mathrm{a}}\right)$ & $\left(2.26^{\mathrm{a}}\right)$ & $\left(224.06^{\mathrm{a}}\right)$ \\
\hline
\end{tabular}

${ }^{a}$ The experimental values are also shown in parentheses for comparation. 